\title{
Advanced Energy-Efficient Filtration: \\ Fan Filter Unit
}

Final Report (LBNL-57727)

To

\section{California Energy Commission}

2005

Tengfang Xu 


\section{Contents}

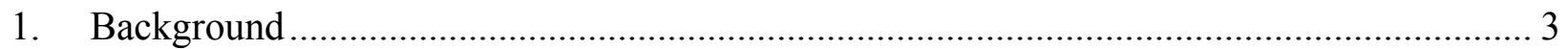

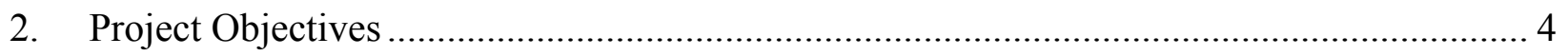

3. Project Activities and Major Outcomes ..................................................................... 4

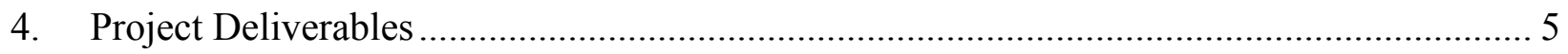

5. Summary of Phase-one Demonstration Project ..................................................... 6

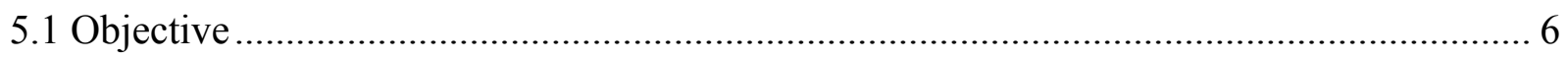

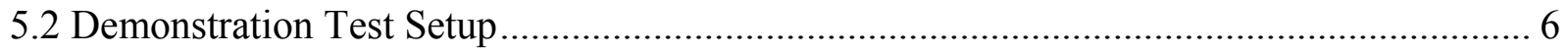

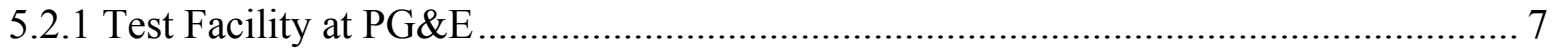

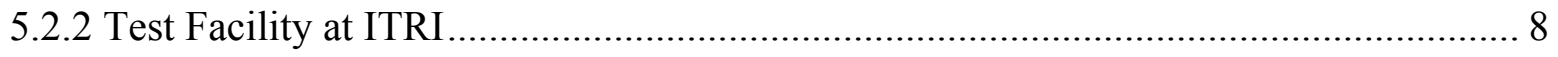

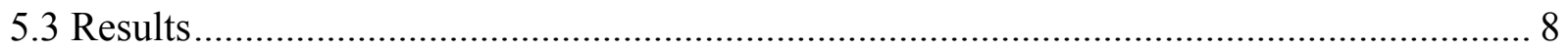

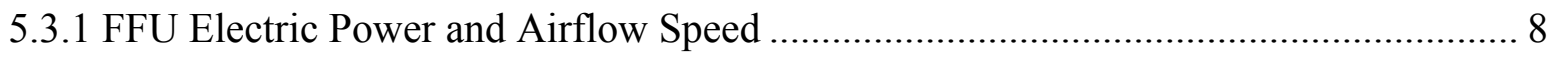

5.3.2 FFU Pressure Rise and Airflow Speed ........................................................ 9

5.3.3 FFU Total Pressure Efficiency and Airflow Speed .......................................... 10

5.3.4 FFU Energy Performance Index (EPI) and Airflow Speed ................................. 11

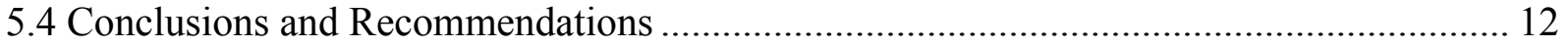

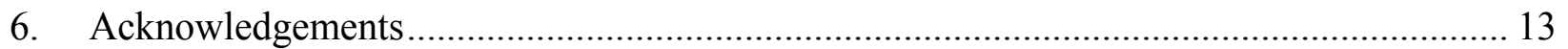

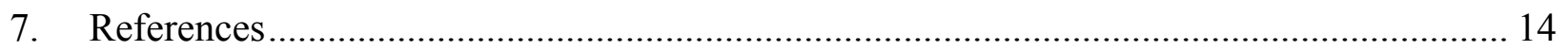




\title{
Advanced Energy-Efficient Filtration: Fan Filter Unit
}

\author{
Tengfang $X u$
}

\section{Background}

With the expectation that the development of a standard method or procedure for testing and reporting performance of fan-filter units (FFUs) will continue in the industry, LBNL proposed to provide technical assistance in the testing method development in this project.

At the early stage of this project, LBNL investigated the levels of interests, expertise, and resources of a list of standard-setting organizations, which potentially would be interested in developing a national, voluntary standard for testing the performance of FFUs. LBNL communicated with the officials or members in the following organizations: Air Movement and Control Association International (AMCA), American Society of Heating, Refrigerating and AirConditioning Engineers (ASHRAE), American Society for Testing and Material International (ASTM International), Institute of Environmental Sciences and Technology (IEST), and other relevant entities. Based upon the evaluation of the levels of interests, availability of expertise and resources, we identified the following key parties and players:

- Industrial Technology Research Institute (ITRI), Taiwan.

- $\quad$ The Air Movement and Control Association International (AMCA).

- Institute of Environmental Sciences and Technology (IEST).

- FFU suppliers and users.

Upon further discussion with the interested parties, and stakeholders that include the members of the Project Advisory Committee and the California Energy Commission, LBNL decided to interact closely with these key players and to develop a draft standard method for testing and reporting energy performance of fan-filter units.

In November 2003, IEST created and formalized a Working Group (WG) consisting of approximately twenty or more experts associated with the industries, standard-setting entities including AMCA, and the government. The IEST WG started to develop the scope of an industrial Recommended Practice (RP) document on the standard method for testing FFU performance. The WG, which is titled "Testing Fan Filter Unit," has since met twice a year and established the collaboration and made voluntary effort by the WG members to develop a Recommended Practice (RP) document for testing FFUs in laboratory setting.

Establishing a testing method to consistently report the energy performance of fan-filter units (FFU's) will help cleanroom owners and designers to make informed choices that consider energy efficiency among other important considerations. Being able to providing comparative 
performance information to owners and designers can facilitate the selection of more energy efficient FFU models. Energy efficiency practice can be encouraged through utility incentive programs, which can be made possible by using the performance data reported from standardized testing, or by establishing minimal performance rating criteria.

\section{Project Objectives}

The objective of this project is to provide assistance in development of a standard test procedure for fan-filter units, which are gaining popularity for use in California cleanrooms. In particular, LBNL carried out collaboration with various stakeholders in the industry and took a lead in developing a draft standard method for testing the energy performance of fan-filter units, and provided assistance to California public utility companies by testing the draft method in PG\&E's testing facility. Through testing more units in the future with a robust standard method, baseline performance information can be developed for use in possible energy incentive programs.

\section{Project Activities and Major Outcomes}

In the course of this project, LBNL collaborated with the ITRI of Taiwan, AMCA, IEST, PG\&E, suppliers and users of fan-filter units. The major activities and outcomes are summarized in the following:

- Developed a draft standard method for testing and reporting performance of fan-filter unit. The draft outline and the first version of the standard test procedure were developed and issued for reviews by the Project Advisory Committee (PAC) members. A second draft was made available on LBNL website for public reviews from April 2004 to June 2005 [1]. Additionally, the second draft was sent to a wide range of stakeholders for additional reviews. Based upon input from the industry and interactions with IEST Working Group 36 "Testing Fan Filter Unit," a final draft of the standard test method was prepared along with in this final report for delivery to the California Energy Commission [2]. The developmental output from the project is well received by the stakeholders and is being integrated into the document on Recommended Practice by a national standard development organization, i.e., IEST.

- Completed demonstration tests at PG\&E's testing facility, San Ramon, California. Partnering with ITRI and PG\&E, LBNL carried out research and the initial demonstration test on testing the draft standard method at PG\&E's facility. This initial demonstration project tested the usability of the draft standard method, and preliminarily demonstrated that testing energy performance of fan-filter units based upon a consistent method was necessary and viable. The use of this draft method has produced useful results that could be adopted to establish a baseline line criteria for energy incentive program in the future.

- In addition, in collaboration with ITRI, LBNL conducted and completed another demonstration test on testing the draft standard method at ITRI's facility, Taiwan. The same fan-filter unit was tested at both facilities. The purpose of the extra effort was to start investigating some of the technical issues affecting the draft standard method, although they are not within the scope of the existing CEC project. This additional research and 
demonstration, in the meanwhile, has identified a number of technical issues that merit further investigations. Being able to address these issues would enhance the robustness of the draft standard test method developed in this phase so that its adoption by various users could be maximized.

- Overall, synergistic activities in the duration of this project have generated interests and raised energy-efficiency awareness among fan-filter professionals. LBNL's interactions with the industry, e.g., IEST, SEMI, Sematech International, and utility companies, have enhanced industry liaisons (suppliers and end-users). Through continued interactions with the stakeholders (e.g., involvement with the IEST working group and utility companies), energy-efficiency awareness can be continuously enhanced among the professionals and current practices in California cleanroom industries can be expected to improve.

\section{Project Deliverables}

Project deliverables include the following:

- Completed the draft standard test procedure for fan-filter units. The final draft of standard test procedure for fan-filter units was developed, and was made available in the LBNL web page. The development has stimulated significant interests from the stakeholders including users, suppliers, and various professional organizations.

- Completed the phase-one demonstration project - to test the standard test procedure. As contracted, LBNL has completed the phase-one demonstration project at PG\&E's testing facility. In addition, in collaboration with ITRI, LBNL also completed an extra research and demonstration project at ITRI's facility. A summary of the phase-one demonstration project - to test the standard test procedure, is included in this report.

- PG\&E has suggested that once an energy performance test standard is available, demand side management programs would like to include high efficiency fan filter units in possible rebate programs. In this project, LBNL provided technical assistance through various activities, including poster, meetings, and the phase-one demonstration at PG\&E's facility in the course of developing a baseline for its possible use in establishing a rebate program.

In addition, LBNL has produced the following material resulting from synergistic activities and collaboration with others $[3,4,5,6,7]$. The material has been distributed among and well received by the stakeholders and the industry.

- An award-winning journal article on the fan-filter unit work, as a result of collaborating with ITRI in testing FFUs [3].

- Several articles were published in IEST, SEMICON, and Controlled Environments Magazine (formerly A2C2), in collaboration with ITRI in this phase of project. The articles addressed findings from testing the FFUs based upon ITRI's data and focused on energy performance of FFUs to inform and educate cleanroom professionals. The publications and associated presentations were well received by the industry $[4,5]$. 
- A poster and various presentations were prepared and distributed to California Public Utilities [7]. The concept of performance testing method was introduced to the industry, including three utility companies in California, SEMATECH International, and IEST [3, 4, 5, $6,7]$.

\section{Summary of Phase-one Demonstration Project}

\subsection{Objective}

The main objective of the demonstration is to test the draft standard method being developed at Lawrence Berkeley National Laboratory [1], in PG\&E's facility. In collaboration with ITRI, LBNL conducted additional research and demonstration at the ITRI facility, Taiwan.

This report includes: 1) demonstration of testing the draft standard test method for aerodynamic and energy performance in two laboratory-testing facilities, and 2) comparing the tests and suggesting areas for future investigations.

\subsection{Demonstration Test Setup}

The FFU used in the demonstration project consisted of a small fan, and a HEPA filter, and a sealed box sized to fit into standard cleanroom ceiling grids $2 \mathrm{ft}$ by $4 \mathrm{ft}$ as shown in Figure 1 .

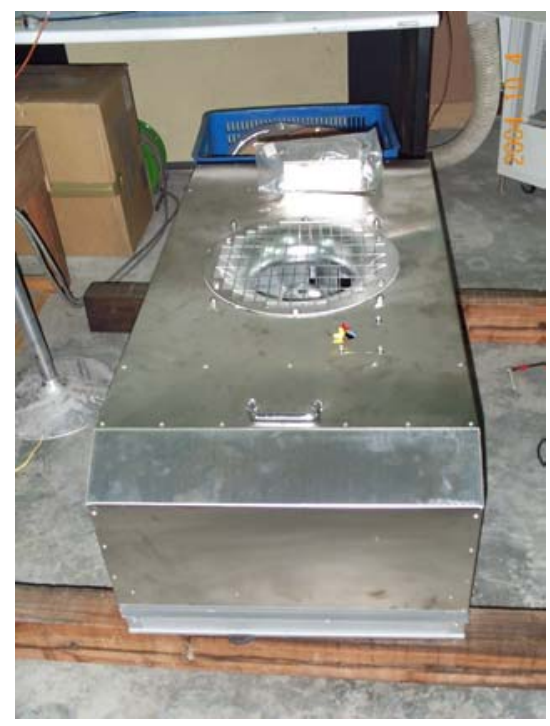

Figure 1 Fan-filter Unit Used in the Tests

The FFU modulation device was integrated with the FFU for setting fan-wheel rotation speeds (Rotation Per Minute, RPM). The fan-wheel motor in the FFU was set at different RPMs during the testing to obtain performance data. At each RPM setting, the FFU was tested at various pressure-rise across the unit, which was modulated by adjusting damper positions. The ambient conditions and the airflow conditions were recorded and were used for the air density conversion to the equivalent standard condition (i.e., $1 \mathrm{~atm}, 20^{\circ} \mathrm{C}$ ). We assume that the airflow was isothermal, although a small fraction of heat was generated from fan motors, which was 
transferred to the airflow. The reported performance data were based upon the standard air condition, i.e., with the air density of $1.20 \mathrm{~kg} / \mathrm{m}^{3}$, in order to directly compare the energy and aerodynamic performance.

Through interactions with collaborators, we determined the following parameters to include in the testing and reporting:

- Unit's airflow rates (or actual airflow speeds).

- Pressures rise across the unit.

- Total electric power demand.

\subsubsection{Test Facility at PG\&E}

The FFU tested was mounted vertically on the inlet end of an air chamber for airflow measurement. The chamber contains a multiple-nozzle bank for recording airflow rates through the tested unit. Figure 2 shows the floor plan of facility setup at PG\&E. The airflow through the FFU was supplied and pre-filtered from the atmosphere upstream of the FFUs. A booster fan and a damper were installed at the chamber outlet to modulate air pressures across the FFU so that the airflow rates were controlled.

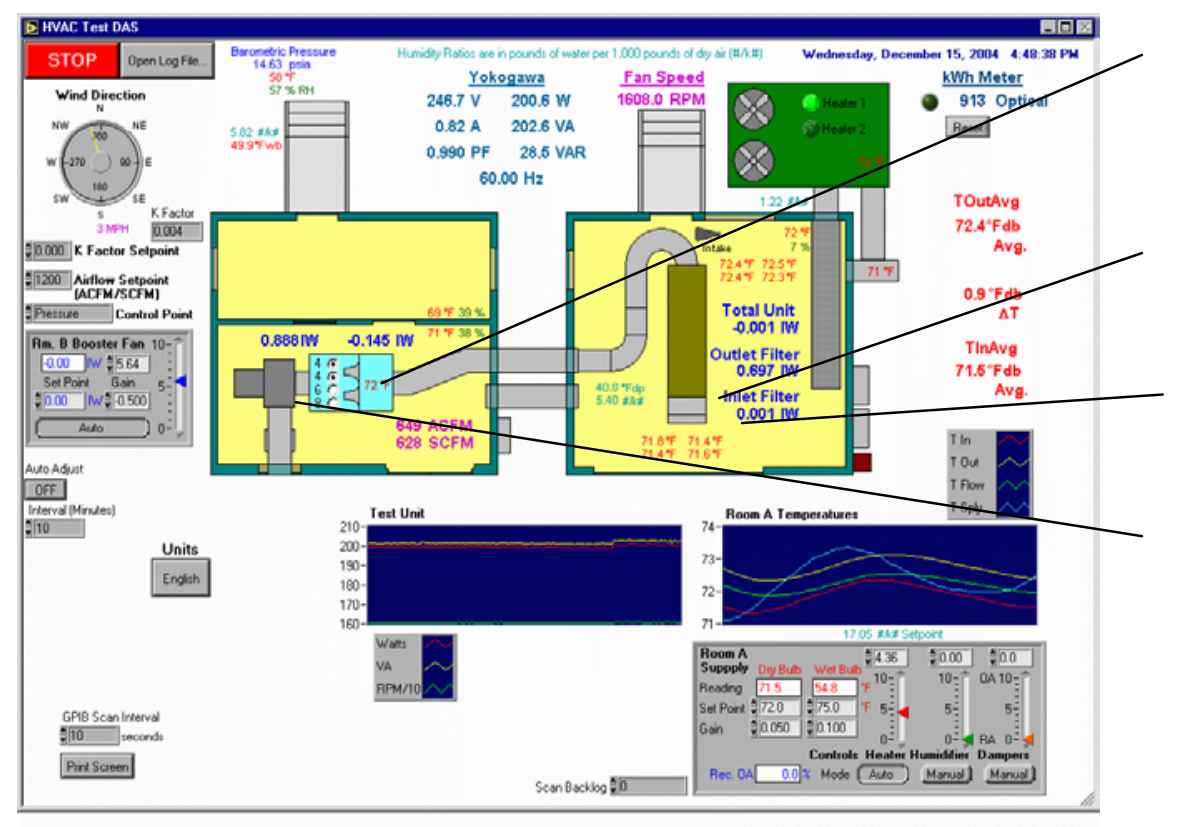

Chamber with airflow nozzles

Fan-filter unit and pre-filters

Ambient air supply

Booster fan and dampers

Figure 2 Laboratory measurement layout at the PG\&E facility 


\subsubsection{Test Facility at ITRI}

The FFU tested was mounted vertically on the exit end of the air chamber (

Figure 3). The chamber contains a multiple-nozzle bank for recording airflow rates through the tested unit.
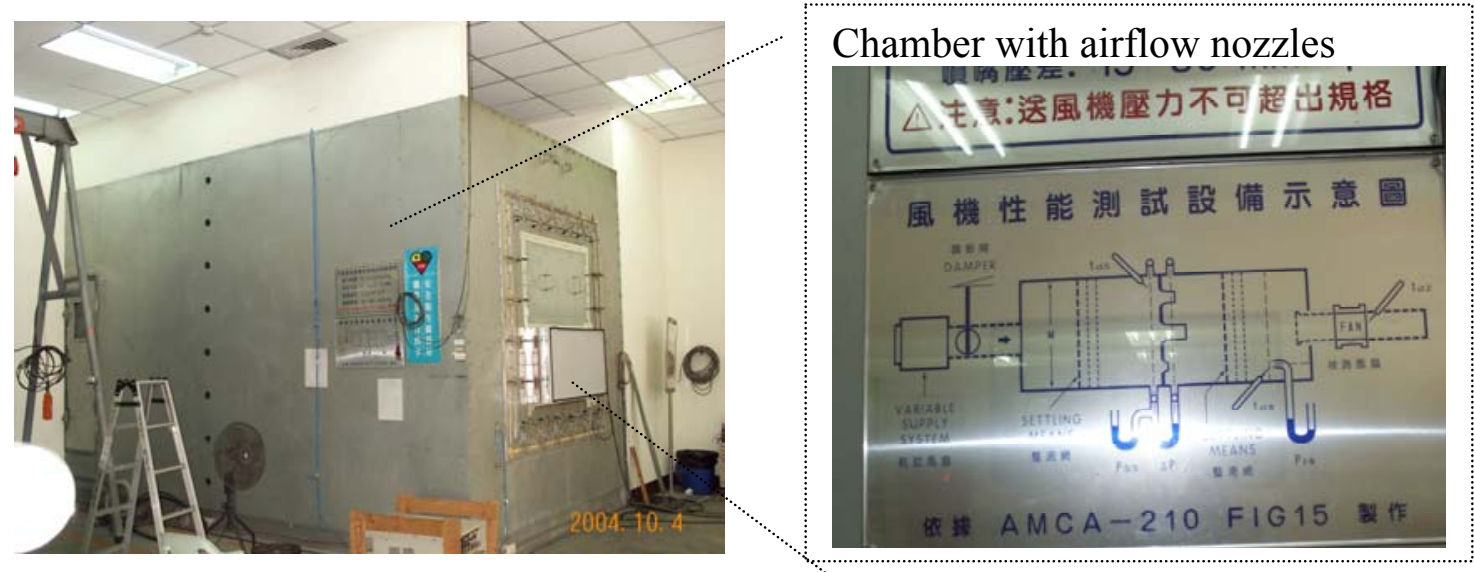

Fan-filter unit

Figure 3 Laboratory measurement layout at the ITRI facility

Figure 3 shows that the air from the downstream of the FFU was discharged to the atmosphere from the filter face. A booster fan and a damper were installed at the chamber inlet to modulate the airflow across the FFU. Exit airflow of the FFU discharged into a room with the air at atmospheric conditions.

\subsection{Results}

\subsubsection{FFU Electric Power and Airflow Speed}

Figure 4 shows the measured FFU electric power demand as it correlated with the airflow speeds at FFU exit at two fan rotation speeds, i.e., 1630 RPM and 1520 RPM, respectively. From the results obtained from PG\&E's facility, it's clear that the electric power demand increased with the increase in airflow speeds within the operating range of the FFU for both RPMs. In addition, the electric power demand was higher with the higher RPM at any given airflow speed within the FFU's the operating range.

On the other hand, measurement results of electric power demand at PG\&E's facility were slightly different from those obtained from ITRI's facility. Because the actual power supplies at the two facilities were different as a result from facility constraints, the measured data obtained from both facilities was not sufficient to address the issue on the repeatability. A power supply with 240-Volt and 60-Hertz was available and used in PG\&E's facility, while a power supply with 220-Volt and 60-Hertz was available and used in ITRI's facility. The constraints of the 
power supplies offered at the two test facilities and the difference in the actual RPMs of the fan wheels probably contributed to the observed difference in the electric power demand for the same unit, which would have been expected at the same airflow rate.

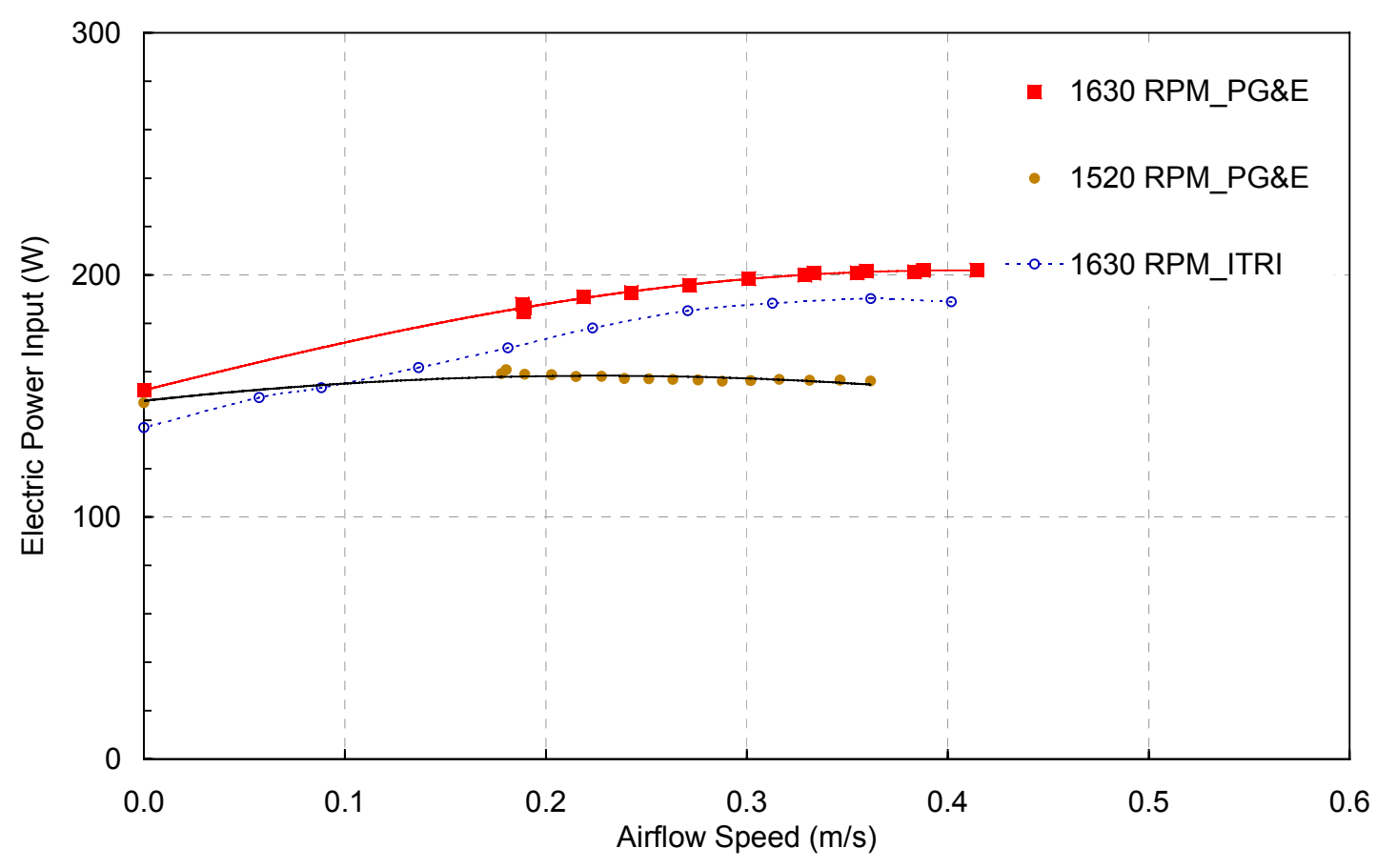

Figure 4 Total Electric Power Demand vs. Airflow Speed at FFU Exit

\subsubsection{FFU Pressure Rise and Airflow Speed}

Figure 5 shows the measured FFU pressure rise versus airflow speeds at FFU exit at two fan rotation speeds, i.e., 1630 RPM and 1520 RPM, respectively. From the results obtained from PG\&E's facility, it's clear that the FFU pressure rise decreased with the increase in airflow speeds within the operating range of the FFU for both RPM setting. In addition, the FFU pressure rise across the unit was higher with the higher RPM at any given airflow speed. For a given airflow speed, the pressure rise across the FFU was maximized by operating the unit at its highest RPMs.

On the other hand, pressure rise across the FFU at PG\&E's facility was slightly different from that obtained from the ITRI's facility at any given airflow speed. The significance of the observed difference and the possible influence from the constraints in equipment layout and power supplies is a complex issue and should become a subject for future investigations. 


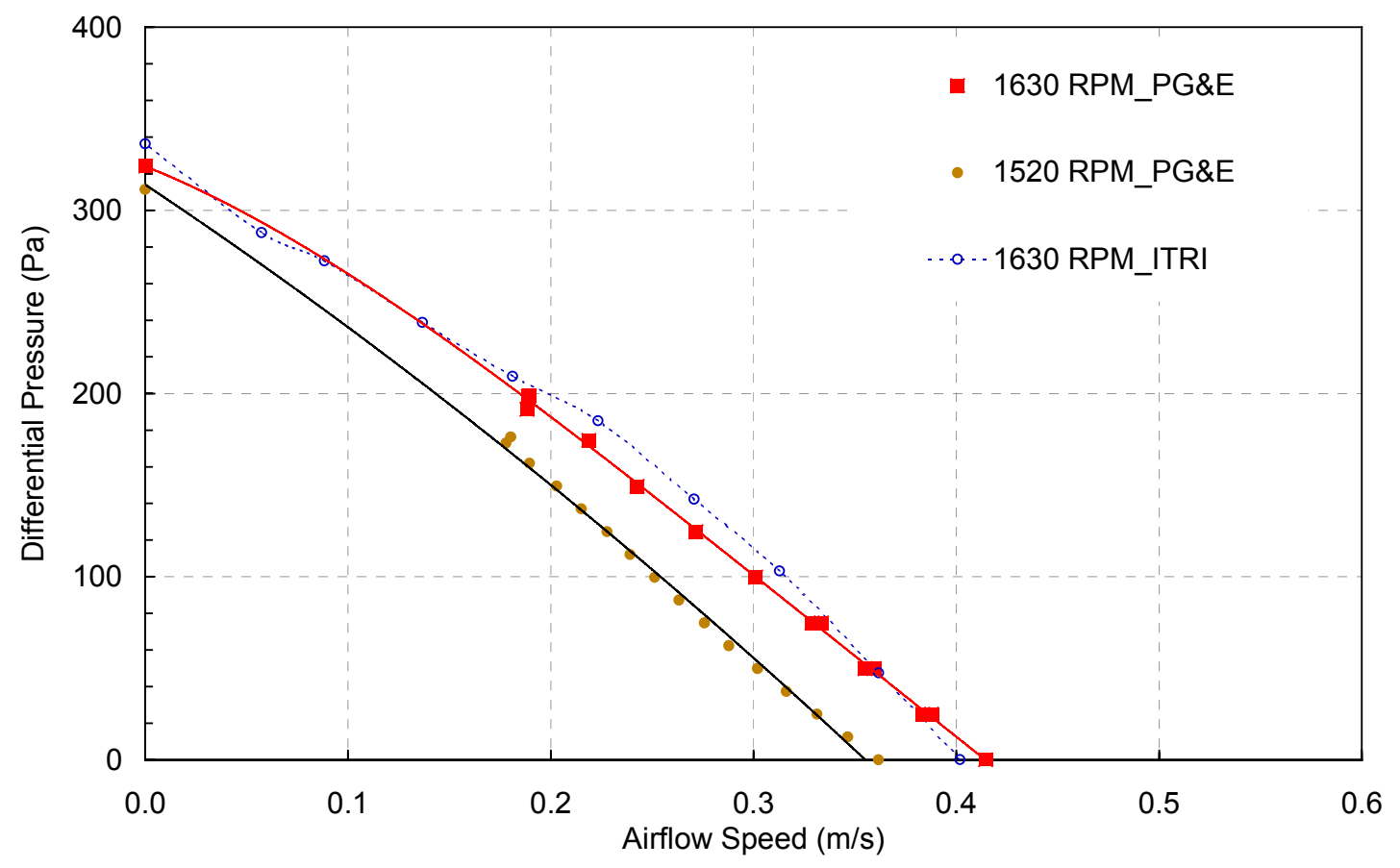

Figure 5 FFU Pressure Rise vs. Airflow Speed at FFU Exit

\subsubsection{FFU Total Pressure Efficiency and Airflow Speed}

The total FFU power efficiency $\left(\mathrm{E}_{\mathrm{t}}\right)$ is defined as the actual airflow dynamic power divided by the total electric power input to the FFU unit. The total FFU power efficiency includes electrical efficiency and mechanical efficiency of the whole FFU unit and it takes into account fan motors, transformers, etc.

$E_{t}=P_{t} Q / W$

Equation [1]

where

$\mathrm{P}_{\mathrm{t}}$ is the FFU pressure rise $(\mathrm{Pa})$

$\mathrm{Q}$ the airflow rate $\left(\mathrm{m}^{3} / \mathrm{s}\right)$, and

$\mathrm{W}$ is the total electric power input to FFU (W).

Figure 6 shows the performance curves of the FFU in terms of total pressure efficiency as it changed with the airflow speeds at the FFU exit for two different RPMs. The total pressure efficiency of the FFU varied considerably at various rotational speeds and airflow speeds. For a given airflow speed, the total pressure efficiency may be maximized by operating the unit at its highest RPM in general.

Additionally, the calculated values of total pressure efficiency of the unit based upon the ITRI's facility tended to be slightly higher than those obtained from PG\&E's facility. This was most likely due to the lower electric power supplied (Watt) to the FFU unit tested at the ITRI facility 
at a similar operating condition, even though a slightly higher pressure-rise across the FFU was developed for certain range of airflow rates (speed). Because the unit was operating by different power supplies, a same output (total pressure efficiency) at the same airflow speed should not be expected in the comparison. Adding to the possible variations in fan-wheel rotation speeds, the effect of test rig configurations on the measured results could not be sufficiently determined from the data generated from the facilities in this study. The effect of test rig configurations will need to be determined through additional investigations.

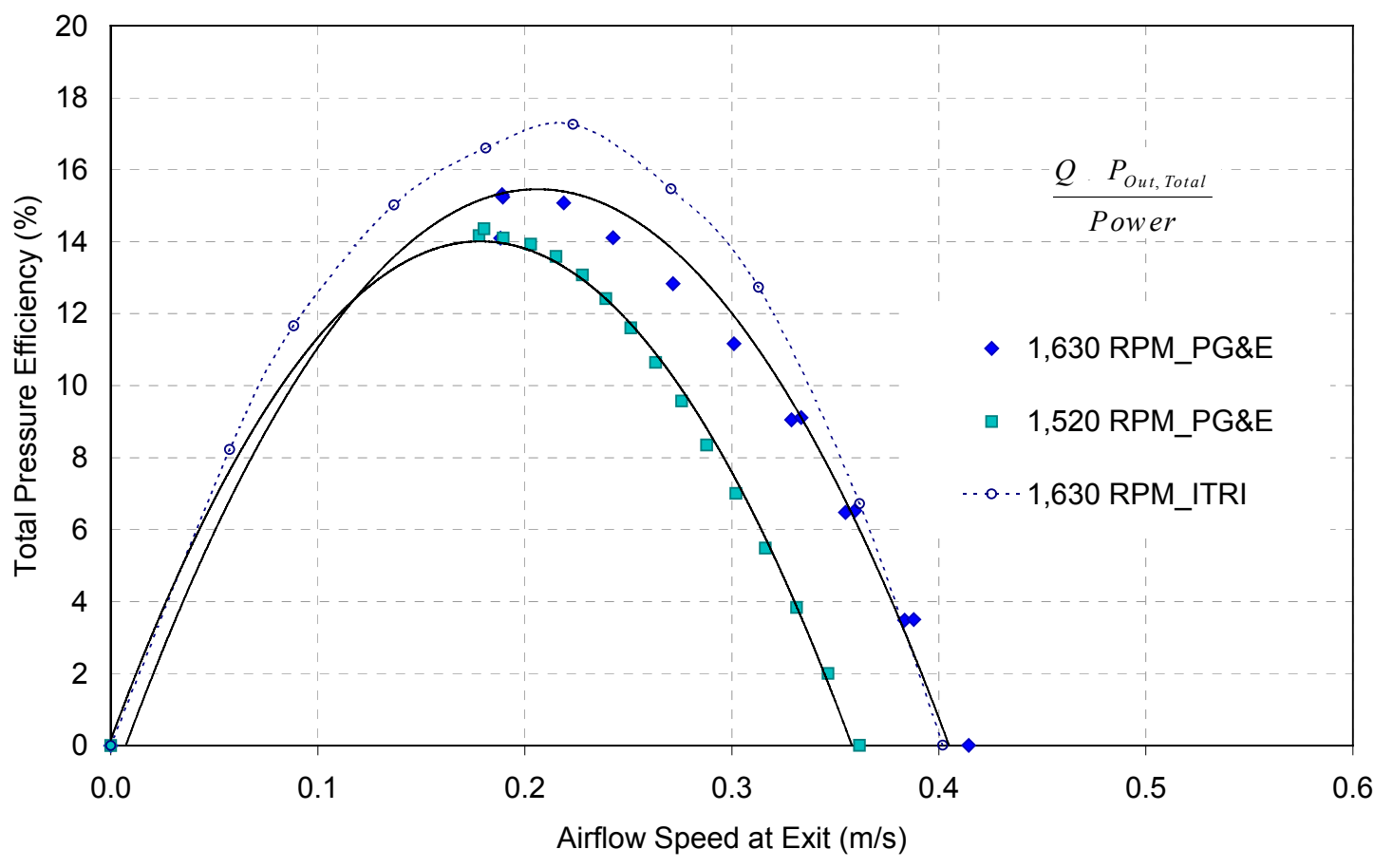

Figure 6 Total Pressure Efficiency vs. Airflow Speed at FFU Exit

\subsubsection{FFU Energy Performance Index (EPI) and Airflow Speed}

Figure 7 shows the measured Energy Performance Index (EPI, FFU electric power demand per airflow rate) under a range of the airflow speeds at unit's exit. The EPI values decreased with the increase in airflow speeds. In this regard, the FFU operated more efficiently in delivering the airflow at a higher airflow speed. This exhibited a similar trend found for other FFUs tested by ITRI in a previous study.

On the other hand, this indicates that the fan inside the FFU with wider damper opening would not have to work as hard as it would have to, compared to other cases in which the systemresistance increases (i.e., a narrower damper opening). In general, for a given airflow rate (speed), the EPI value may be reduced by operating the unit at a lower RPM. 
Similar to the trend observed in total pressure efficiency, the calculated EPI values of the unit based upon the ITRI's facility tended to be slightly lower than those obtained from PG\&E's facility. This was most likely due to lower electric power supplied (Watt) to the FFU unit tested at the ITRI facility at a similar operating condition. Because the unit was operating by different power supplies, a same EPI value at the same airflow speed would not be expected when comparing the results between the two facilities, however.

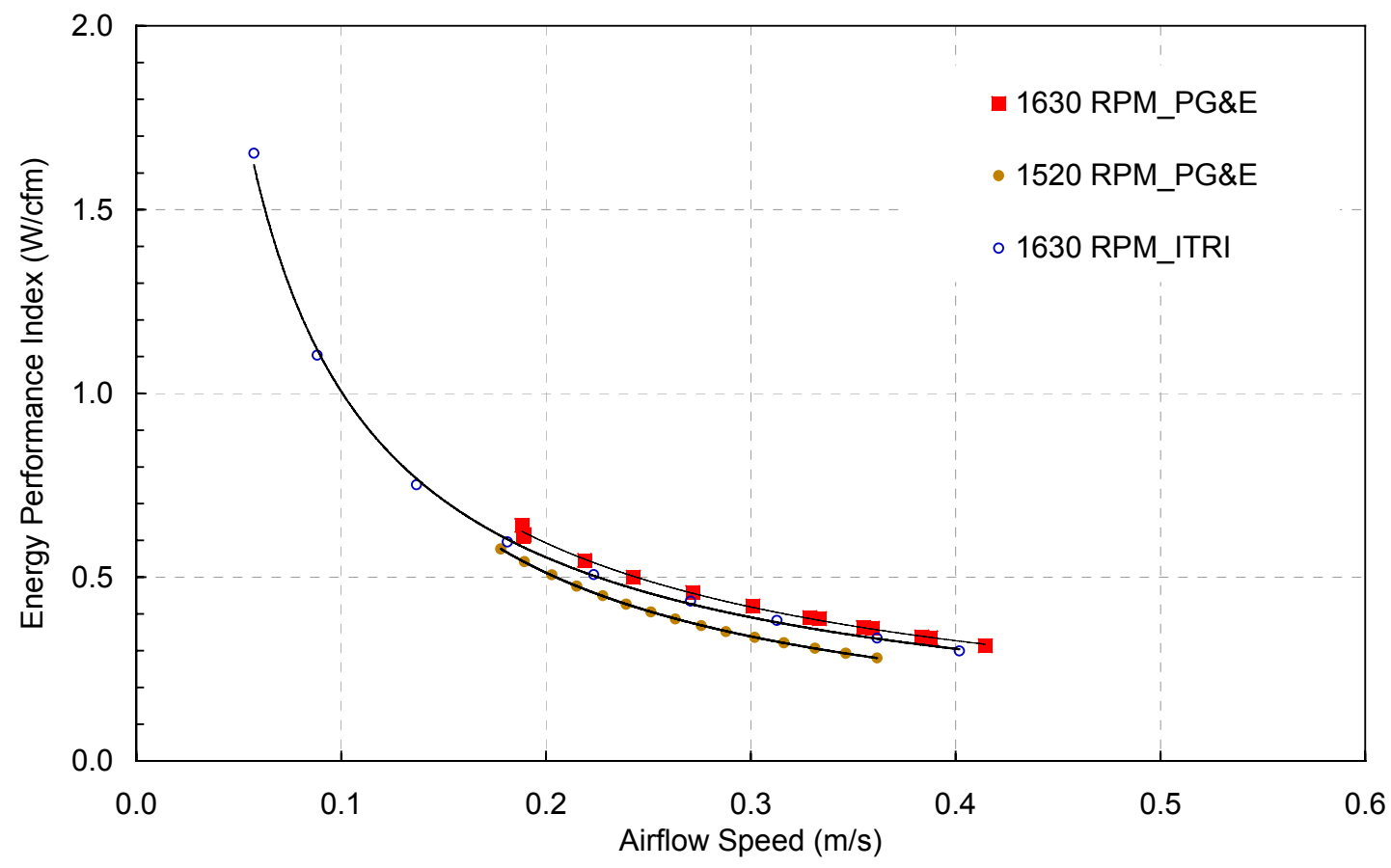

Figure 7 Energy Performance Index vs. Airflow Speed at FFU Exit

\subsection{Conclusions and Recommendations}

Laboratory testing of FFU energy performance can provide useful data for suppliers and end users to understand the performance of FFU products. Based upon this draft standard test method, it's feasible for users and suppliers to obtain energy performance in a consistent way. LBNL has completed the phase-one demonstration project at PG\&E's testing facility.

In addition, in collaboration with ITRI, LBNL also completed an extra research and demonstration project at ITRI's facility. The additional demonstration was intended to start initial examination of the variance such as different configurations of test rigs and device. In both demonstrations, the same fan-filter unit was tested using the draft standard test method developed. 
Demonstration testing at both facilities followed the options described in draft standard method in order to consistently collect the same performance parameters and to report the results using the same metrics. The measured parameters and calculated metrics included pressure-rise across the unit, energy performance index, and total pressure efficiency, under various operating conditions. Comparisons of the measured metrics calculated based upon the tests within each facility were made, and they demonstrated clear correlation between energy performance, airflow rates, and pressure rise for the unit under different conditions. The tests demonstrated that users were able to follow the protocols developed in the draft standard method and obtain comparable results.

Because of the constraints at PG\&E and ITRI facilities (e.g., different power supplies, limitation in testing space and rig configuration), the experimental data obtained from both of the facilities, however, did not appear to be sufficient to address the issue on repeatability between the two facilities. The effect of test rig configurations and device will need to be determined through additional investigations.

A second-phase of demonstration is necessary to understand technical issues associated with configurations of testing rig and device, to refine the draft standard method, and to test more units to establish the baseline performance for energy-incentive program. Through the additional research and demonstration tests in collaboration with ITRI, a number of technical issues are initially identified and are recommended for future investigations. The following enlists some of the important recommendations for future investigations associated with the test method, test set up, and device:

- Examine the significance of difference between FFUs to be place in horizontal position vs. vertical position

- Examine the significance of difference between FFUs to be placed at downstream vs. upstream of the airflows

- Examine the significance of difference between FFUs with various power supplies (voltage, frequency, etc.)

- Examine the significance of difference between FFUs using various speed-controllers (constant-speed, variable speed drive, etc.)

- Examine the significance of difference between FFUs

- Examine the sensitivity of measured results in airflow rates and pressure-rise using various flow measurement methods and measurement locations

- Investigate the uniformity of airflows from a FFU

- Investigate the performance effect of various FFU design, filter type, etc.

\section{Acknowledgements}

The project is funded by the California Energy Commission's Industrial section of the Public Interest Energy Research (PIER) program (http://www.energy.ca.gov/). This work was supported by the Assistant Secretary for Energy Efficiency and Renewable Energy, Office of 
Building Technology, State, and Community Programs, of the U.S. Department of Energy under Contract No. DE-AC02-05CH11231. The author would like to extend thanks to Robert Davis and Jim Yang of PG\&E, and Dr. Chao-Ho Lan of ITRI for providing assistance and comments in the research and demonstration.

\section{References}

[1] $\mathrm{Xu}, \mathrm{T} .2004$. Laboratory Method of Testing Energy Performance of Fan-Filter Units, Version 1.2 (2004, public reviewed). Lawrence Berkeley National Laboratory Report, LBNL-54626, Berkeley, California.

[2] Xu, T. 2005. Laboratory Method of Testing Energy Performance of Fan-Filter Units, Version 1.3 (2005, refined upon additional reviews). Lawrence Berkeley National Laboratory Report, LBNL-54626, Berkeley, California.

[3] Xu, T. and M. Jeng. 2004. Laboratory Evaluation of Fan-filter Units' Aerodynamic and Energy Performance. Journal of the IEST, Volume 47: 116-120. The Institute of Environmental Sciences and Technology (IEST), 5005 Newport Drive, Rolling Meadows, Illinois, October 2004. Lawrence Berkeley National Laboratory Report, LBNL-54250, Berkeley, Calif.

[4] Gale, S. 2004. FFUs: Setting a course for energy efficiency, Special Report, Cleanroom Magazine, September 2004, http://cr.pennnet.com/Articles/Article Display.cfm?Section=Articles\&Subsection=Display\& Article ID $=211810$

[5] Xu, T. 2004. Introducing a Standard Testing Method for FFUs, Controlled Environments (Formerly A2C2), http://www.cemag.us/articles.asp?pid=469, September 2004.

[6] M. Jeng, T. Xu, C. Lan. 2004. Toward Green Systems for Cleanrooms: Energy Efficient FanFilter Units, Proceedings of SEMI Technical Symposium: Innovations in Semiconductor Manufacturing (STS: ISM), SEMICONÆ West 2004, San Francisco, CA, Semiconductor Equipment and Materials International, July 2004. LBNL 55039.

[7] Xu, T. 2004. Developing a Standard Method For Evaluating Fan-Filter Unit Performance Applications in Utility Incentive Programs. Poster distributed to three major California utilities, California Energy Commission, and other stakeholders. 